\title{
CONNECTING COMMUNITY ORGANISATIONS FOR DISASTER PREPAREDNESS
}

\author{
VALERIE INGHAM \& SARAH REDSHAW \\ Charles Sturt University.
}

\begin{abstract}
After fires swept through the lower Blue Mountains of NSW in October 2013 and destroyed over 200 homes, a research project was initiated and titled 'Community Connections: Vulnerability and Resilience within the Blue Mountains'. Reported in this article are the results of eight in-depth interviews conducted with local community leaders. They were asked to reflect on their leadership experiences before, during and after the fires. The research clearly demonstrates that prior to the fires there were no formal connections between local emergency services and local community organisations. Each had limited knowledge of the other in terms of skills, capacities, scope and available resources. This article will elaborate on the lessons learned by the community leaders interviewed. Just as collaborative bonds were finally being formed and combined initiatives had begun to bear solid results - reflected in higher levels of householder disaster preparedness, recovery funding ran out. This article highlights the lessons learned, and includes the importance of maintaining a formalised and continuous connection between emergency services and community organisations. The research recommends that disaster preparedness be embraced as a part of 'core business' by community organisations, and that multi-stakeholder connections be forged and strengthened through collaborative community engagement initiatives at the level of local disaster planning and preparation. Both recommendations contribute to the paradigm shift anticipated by Australia's 'National Strategy for Disaster Resilience'.

Keywords: community resilience, disaster management, shared responsibility.
\end{abstract}

\section{CONTEXTUAL BACKGROUND}

The Blue Mountains are in NSW, Australia, a two-hour drive west of Sydney. The Blue Mountains Local Government Area (LGA) is surrounded by World Heritage dense national park and has a unique geography of 27 settlements along a $100 \mathrm{~km}$ ribbon development stretching across the top of a mountain ridge. The population of 80,000 residents has a predominantly older demographic. There is a greater proportion of workers, aged over 50 years and of post-retirement age, than that of Greater Sydney [1]. Home to stunning surrounds and distinctive landscapes, many tourists and Australians alike make day and overnight visits to the region [2].

Due to the unique location of the Blue Mountains, many members of the local community, in particular older, vulnerable and at risk residents, face specific challenges in a disaster. These challenges include road closures, the halt of public transport and power outages, usually as a result of bushfire or severe storms. This article stems from a larger research endeavour, Community Connections: Vulnerability \& Resilience in the Blue Mountains [3]. The overarching aim of the Community Connections research was to determine the social support and networks of the most vulnerable in the Blue Mountains community and thus inform strategies to increase overall community resilience. The Community Connections research highlights the importance of maintaining connections between services and the importance of shared responsibility to support vulnerable residents, both in day to day life as well as in situations of natural disaster or local emergency.

Each year, many communities around Australia are impacted by a range of natural hazards, including bushfire, floods and severe storm. To mitigate the effects of these situations and to 
enable appropriate and timely response for affected communities the Federal Government enacted the National Strategy for Disaster Resilience (NSDR [4]), which recognises that 'disaster resilience is a shared responsibility for individuals, households, businesses and communities, as well as governments' (p. ii). Importantly, in the NSDR the community and the not-for-profit sector are recognised, for the first time, as having a role in emergency management activities involving planning, response and recovery from disasters. In October 2013, three fires proved to be a watershed experience for local Blue Mountains emergency services and community organisations alike. The three fires, the State Mine Fire, the Mount York Rd Fire and the Linksview Road Fire, burnt out over 65,000 hectares (160,000 acres), destroying and damaging over 300 homes and directly impacting local schools, businesses and other services. Despite the edict of the NSDR and the frequent threat and occasional fire, the local community found itself relatively unprepared for the scale and devastation of this event. In the following section the events of the October 2013 fires are summarised.

\subsection{The October 2013 fires}

On Wednesday, 16th October 2013, a military exercise sparked the State Mine Fire, which rapidly escalated into a threat for Upper Mountains residents. Due to the danger of explosives and the 'no fly zone' in the air space above the army base, the fire spread quickly into rugged, inaccessible land destroying 5 houses and over 55,000 hectares of bushland [5]. The following day, the Mount York Rd Fire started in the Mount Victoria area. Despite being initially contained, the fire crossed containment lines and destroyed ten houses along with other structures and vehicles [5]. A short time later on the same day a third fire commenced in Springwood, a densely populated lower mountains residential area. Called the Linksview Road Fire, it was sparked by strong winds which caused a rotting tree to fall onto powerlines [6]. The Linksview Road Fire quickly spread through the villages of Springwood, Winmalee and Yellow Rock, destroying 193 houses and causing damage to many more in a few short hours. The size, scale and speed of the fires caught local communities completely off-guard. Many residents of the Linksview Road Fire relocated to designated evacuation centres. Others chose, or in many circumstances were not able, to leave and instead stayed and defended property. Local schools were either evacuated or went into lock down $[4,7]$.

Throughout the following week the fires continued to cause significant destruction, with firefighters trying a range of techniques to control the blazes. Community meetings were held throughout the region during this time and were attended by many local residents. By October 20th the NSW Premier, Barry O'Farrell, had declared a state of emergency [8]. Making this declaration provided emergency services with powers to demolish burned buildings and to evict community members from their homes for their own safety. On Wednesday, 23rd October, intensified weather conditions led to the Minister for Emergency Services, Mike Gallagher, advising 'residents who did not have a bushfire survival plan' to leave the Blue Mountains [9]. On this day, all Blue Mountains schools were closed so that families could stay together [10]. Though no loss of life was suffered, the fires had a devastating impact on the local region with significant loss and damage to property. In addition to the large insurance bill, the Insurance Council of Australia has estimated total insurance losses to be in excess of $\$ 180$ million [11]. While a majority of affected residents were insured, a significant proportion did not have an insurance policy that adequately covered the rebuilding of property and replacement of contents [12]. The contamination of asbestos further added to the disaster, with many home owners and members of the public refused access to their destroyed 
homes [7]. Additionally, the fires had a devastating impact on the local tourism sector. Despite prominent tourist sites such as the Three Sisters not being impacted, a downturn in visitors in the weeks and months following the fires cost the local economy over $\$ 100$ million [13].

\subsection{The recovery process}

The work that was undertaken in the immediate response and recovery phase in the Blue Mountains brought together two sectors, the emergency management sector and the community services sector, which prior to this time had very little awareness or understanding of one another. Despite the frequent threat and occasional fire, the community services sector was significantly underprepared for emergencies with little or no knowledge of emergency manuals, plans or evacuation. The community services sector was not represented on the Local Emergency Management Committee, and most people were unaware that it even existed. Similarly, the local emergency services sector was unfamiliar with the activities and services provided by local community services, and, in particular, their connections with vulnerable individuals and their needs. Thus, while there was the odd connection between local emergency and community services, it was limited and informal.

The lack of knowledge and understanding that the emergency and community services had of each other resulted in a discordant recovery process in the Blue Mountains and a rather steep learning curve for both sectors, which found common ground in the establishment of the Blue Mountains Resilience and Preparedness Working Group.

In the following sections we provide a contextual background to the local community and emergency services in Australia. The section culminates in a summary of the potential difficulties faced when connecting these two sectors.

\subsection{Local community services in Australia}

The rise of local community service organisations, otherwise known as neighbourhood or community centres and neighbourhood or community houses, can be traced to the $1960 \mathrm{~s}$ and 1970s. The emergence of these organisations was influenced by various movements including the rise of community development, second wave feminism and other social reforms [14-17]. Prior to the 1970s, most social services, along with health and recreational amenities, were provided by faith-based or benevolent organisations [14, 15]. Rooney highlights the difference between local community services and previous service models. Compared to the altruistic services provided by benevolent/faith-based institutions, local community organisations were run and managed in their community, embraced community development and self-determination and aimed for social justice [15]. Today, local community organisations continue to espouse similar goals and principles. Peak bodies, such as the Local Community Service Association [18] and the Australian Neighbourhood Houses and Centres Association [16], identify values and practices common to all local community services to include social inclusion, community development, local participation, community management, operating from the bottom up or at grassroots level, and supporting the most disadvantaged and socially isolated community members. Izmar, et al. [19] argue that these organisations are a crucial part of the social infrastructure of a local community and that these services can meaningfully support community members as 'centres that can be quickly mobilized, expanded or readjusted to respond to local needs, emerging issues, or opportunities' (p. 6). 
Another feature of many local community organisations is the limited sources of income they have to deliver services and support. In a survey of member organisations, ANCHA [16] identified that nearly $60 \%$ of Neighbourhood Centres had an annual income of less than $\$ 250,000$ and $52 \%$ do not employ any fulltime staff. In line with many other non-profit institutions, most of the funding for local community organisations comes from government sources [20]. The process through which organisations receive funding has changed substantially since local community organisations commenced operating, a transition that is illustrated by Lyons [14] typology of funding relationships. The 'Competitive Tendering' model [14], whereby Governments set strict standards and organisations compete for short term contracts to deliver services, is now the situation faced by local community organisations. It has been widely acknowledged that these often haphazard and competitive funding arrangements present significant difficulties for organisations to continue to meet the needs of local communities $[21,22]$.

\subsection{Local emergency services in Australia}

In order to highlight the issues raised when connecting the local emergency services and community organisations, we briefly touch on the formal origins of emergency management within Australia. This is important because the federally mandated emergency management arrangements in Australia have a flow-on effect right down to the grass roots level of an individual Local Government Area and the various communities within.

Emergency management originates from civil defence strategies and practices established during World War II and the Cold War [23]. Following the impact of the crises in the late 1960s such as the Tasmanian bushfires, and the Granville train crash in Sydney and Cyclone Tracy in Darwin in the early 1970s, Australia turned its attention to improving prevention and planning for disaster. The establishment of comprehensive community-based recovery management facilities and services following the 2003 Canberra bushfires and Cyclone Larry in Queensland in 2006, demonstrate the importance that recovery management now receives from emergency services and local government authorities [24, 25]. More recently, the 2009 Victorian Bushfires Royal Commission [26], the 2011 Queensland Floods Commission of Inquiry [27] and the 2011 Keelty report on the Perth Bushfires, 'A shared responsibility' [28], have highlighted various issues relating to shared responsibility and community sector participation in emergency management. In various local emergency service programmes and survival brochures, community members are encouraged to consider how they would survive without the availability of power, water, food or transport for an extended length of time. In the Blue Mountains prior to October 2013 there was plenty of information available, however there were no outreach programmes or systematic approaches to dissemination or education in the form of accessible programmes for vulnerable or at risk residents. This was the situation before the Linksview Road Fire of 2013, as there were no formal connections between the community and emergency services in the Blue Mountains Local Government Area.

\subsection{When the two sectors meet}

In the light of the literature, we examine the potential difficulties faced when connecting the local community and emergency services in any kind of meaningful way.

\subsubsection{Reconceptualising the role of emergency services within the community}

Emergency management activities across Australia are not always consistent and there are still many areas for improvement $[29,30]$. One area for improvement lies with continuing to 
encourage the paradigm shift from a focus on the emergency services as 'rescuers' and residents as passively waiting to be 'rescued', towards embracing the National Strategy for Disaster Resilience [4] focus on 'shared responsibility'. This paradigm shift is massive and ongoing as, with its paramilitary origins, emergency services operate within a hierarchical model which is at odds with the participatory action model of the community sector, where community engagement depends upon a collegial approach to decision-making.

\subsubsection{Command and control meets collaboration}

Morphing from the rigid structure of command and control to become inclusive of community engagement and equally valuing Non-Government Organisation (NGO) participation in local levels of disaster planning, prevention, response and recovery, is challenging for emergency service organisations, be they career based or volunteer based. The emergency services engagement with community should be taken seriously, as Sewell [31] comments, 'I believe we have moved into a very dangerous place when "consultation" is used as a disguise rather than a genuine interest in engaging the needs of any community, particularly when the outcomes are potentially fatal'. The future safety of many Australian communities relies on a paradigm shift involving societal change. Where possible, each person and household must take responsibility for their own safety and protection in the event of natural disaster.

\subsubsection{Communication and information sharing}

In large-scale emergency response, and, indeed, any emergency response, the dissemination, use and management of information is particularly important. It has been found, for example, that information sharing is easiest when people have received the same information, are in close proximity to each other and have insight into other people's needs [32]. Even as largescale emergency management shifts from rigid hierarchies to more flexible, decentralised management, the central concern remains the reduction of uncertainty [33]. Not only does such a focus result in rather self-evident conclusions (that improved communication improves information quality, for example), but it also fails to address the reality of decision-making in these contexts. Although more information would improve emergency responses, such a focus denies the way decisions in emergency response will almost always involve uncertainty, fragmented knowledge and prompt responses to this (often incomplete) information. In a discussion on structural reform in emergency situations [34], touched on this tension between information control and uncertainty, finding that there is a perceived need for tight, formal and hierarchical structuring of decisions as well as for prompt, often informal and improvised, action. A complete reduction of uncertainty is, in such a field, impossible and so simply asserting that more accurate information would help better decision-making may have limited utility. In order to provide real improvements, emergency management must address how better decisions can be made with this uncertainty.

\section{RESEARCH DESIGN}

The Community Connections research was conducted through a partnership between Charles Sturt University, Blue Mountains City Council, and two neighbourhood centres. Ethical approval was provided by Charles Sturt University in May 2014. The project employed a participatory action framework, facilitated by the community connections of the organisations involved [35]. The involvement of the local council and neighbourhood centres at all levels of the research process meant that the Charles Sturt University researchers could attend meetings relating to the disaster recovery process. The authors' participation as researchers in the Resilience and Preparedness Working Group was pivotal to data collection. Not only did 
it allow participant observation and connections with community and emergency service leaders, it also provided a vehicle to test ideas and theory formation. The Working Group is a focal mechanism for bringing the emergency sector, welfare sector, local council and community sector together to grapple with and strategically approach managing issues around disaster and emergency planning and preparedness.

A qualitative approach to data analysis was employed. Interviews and focus groups with a total of 31 recordings were subsequently transcribed. Data analysis included the manual coding of individual transcripts and key word queries entered into NVivo 10. The findings related to vulnerable people in emergency are already reported [3]. This article concentrates on the connections between local community leaders, representing various community and emergency services, before, during and after the fires, although the focus of their conversation was recovery post the October 2013 fires. There were eight interviews with community leaders based on semi-structured and open-ended discussion starters. The interviews sought information regarding organisational community involvement prior to and after the fires, sources of information and community connections with other organisations, dealing with traumatised people (both their own workers and the community they serve) and their own personal well-being coping strategies.

Two holistic themes emerged and to reflect the complexity of the information and not reduce codes to the state of being disembodied and separated we pursued a coding approach that would reflect the integrated narrative without losing the cohesion between parts [36]. The two major themes to emerge from the data analysis revolve around community and emergency services being integrated in their activities, and continuous in their associations. A third theme, being responsive to the communities they serve, is not reported in this article; this theme encompasses the response and integration of community feedback.

\section{FINDINGS}

The findings weave around two key themes that emerged from the interviews with key community leaders engaged in the recovery process and our participant observation as members of the Resilience and Preparedness Working Group. We offer our findings to provide other like-minded communities a platform to envisage the application of the lessons learned to their unique locations and communities.

\subsection{Integrated approach}

Prior to the October 2013 fires in the Blue Mountains, the role of community organisations in strengthening community resilience for vulnerable people in daily living situations was undervalued and relatively unacknowledged by the local emergency services. Likewise, disaster management was a foreign concept to local community organisations, who had limited knowledge of the local emergency management planning structure and policy.

\subsubsection{Service connections}

It is clear that those community leaders with direct connection to the community through the delivery of various programmes and services to vulnerable individuals had a first-hand experience of the fires - they were out there amongst the action getting their hands dirty. Their role was pivotal in protecting the safety of vulnerable people such as school children and those connected with community organisations, such as Neighbourhood Centres. Their lack of inclusion or representation in the planning and preparation phases, which had been regularly undertaken by the Local Emergency Management Committee, was very noticeable. 
Disconnected from the formal emergency service response, they acted alone and unprepared and as best as they could. When asked if they thought they should be included in a common response focussed on their community connections with vulnerable people as a rationale, they all agreed in the affirmative with one participant stating, 'Because it's community organisations who are in touch, day to day, with real people in the most vulnerable or disadvantaged positions on the ground' (NK p. 3).

As in many other work settings, networking, collective approaches and strong partnerships are highly prized within the community sector. 'If you look at the community sector in the Blue Mountains, which is a very robust and vibrant sector, we have a peak body...so that means that we actually have interaction in all of the inter-agencies' (HK). None of the participants from the emergency services were aware of the community inter-agency activities prior to the October 2013 fires. Peak bodies are key to disseminating information.

\subsubsection{Decision-making strategies}

How decisions were made proved a very interesting discussion point. Within the Resilience and Preparedness Working Group it was apparent that the community sector was acclimatised to the time taken to reach a general consensus through collaborative discussion, while personnel from the emergency services appeared to find the collaborative process almost torturous. It was clear that collaborative decision-making versus hierarchical command and control was initially an unspoken obstacle to progress a decision. The difference in organisational priorities was also an initial point of variance, as initially each representative clung to their organisational mission goals of either Prepare, Respond and Recovery or priorities of community sharing and caring for vulnerable people. It was at least a year before a combined vision for the Resilience and Preparedness Working Group emerged, reflecting the blurred boundaries, concessions, compromises and new points of recently gained common ground.

\subsubsection{Personal well-being and self-care}

We asked community leaders about the strategies they employed to nurture their own personal recovery and dealing with their own difficult emotions. We also asked if, with the benefit of hindsight, what strategies or advice concerning personal self-care they would give to another community leader facing a similar situation.

In relation to the recovery period, we found that leaders talked about pressures experienced due to:

- Time, due to an increase in workload and resultant emotional and physical effects

- Permissions, policy and red tape

- Dealing with staff issues as well as client group issues

- Reduced capacity of individuals, and the organisation as a whole, to cope.

Some leaders found themselves dealing with uncertainty at work and then coping with their own family trauma and disruption. Driving past the destruction and devastation each day on the way to work, spending the day with the victims, and then driving home through burnt out streets, all of which they found constantly traumatising.

\subsubsection{The pivotal role of neighbourhood centres}

The pivotal role of neighbourhood centres in the Australian context was introduced in a broad sense within the literature review. Every neighbourhood centre is a community hub and the 
overarching requirement of neighbourhood centres is to build the capacity of the socially and financially disadvantaged and thus to enhance the capacity of the community.

Each neighbourhood centre has a geographical location that it serves. The interview participants fleshed out this role with details of their activities and all agreed that, 'our strongest focus is on the vulnerable and isolated frail aged and we've got some very vulnerable young, single parents' (HK p. 6).

The purpose of a Neighbourhood Centre was described by one participant:

Information and referral is one of the core purposes of neighbourhood centres, so it is to link community. We focus particularly on the socially and financially disadvantaged by linking them to one another, linking them to social inclusion opportunity, linking them to information that they might require and to other appropriate services for them to meet their needs and function as a meaningful independent member of a connected community. (HK p. 2)

There are six neighbourhood centres in the Blue Mountains. In New South Wales they are core funded by the Department of Family and Community Services. The funding is grant based, 'We're a nongovernment, notforprofit charity, or an incorporated association, but we have charitable and deductable gift recipient status, as do all of the neighbourhood centres in the Blue Mountains' (QT).

The findings demonstrate that the Neighbourhood Centres in the Blue Mountains are particularly well organised and proactive in their communities, as evidenced by the diversity of programs and services they support and the funding they win. Some of the services they are offer include:

- Home and Community Care Program, which is a programme that offers domestic assistance and transport

- Volunteer Home Visitors Service, matches a volunteer to a person in their home, to maintain their social connection and social inclusion, and enhance their connection with their community

- Community Visitors Scheme, which is a very similar scheme to the Volunteer Home Visitors Scheme, where it matches a volunteer to a client in a residential agedcare facility.

- Registered provider of childcare under the national quality standards and framework

- Drop-In Centre for people recovering from or living with a chronic mental illness

- Blue Mountains Home Modification and Maintenance Service, for the frail aged and people living with a disability

3.1.5 Preparedness as core business for neighbourhood centres

As one Neighbourhood Centre Manager stated:

Local grassroots community organisations, such as Neighbourhood Centres, had no formal avenues of contact, connection or links with emergency services. It could be said that there was a perception from both sides, community sector and emergency services, that there was little relevance for either sector connecting plus historical precedents around differing core business. (HK)

With this realisation, the community services within the Blue Mountains are now endeavouring to incorporate disaster preparedness activities into their core business. They understand this as a part of their mandate to build resilient and sustainable individuals and communities, and now regard delivering disaster preparedness programmes as part of their community capacity building core business, not simply an 'add-on' activity. 


\subsection{Continuous approach}

Continuity was seen by all leaders interviewed as key to building a resilient community. Continuity issues were being felt quite acutely at the time of interviewing, as recovery funding was coming to an end. After two years, various roles were being deleted and people with intimate, current experience of the recovery process were facing the prospect of unemployment. The loss of knowledge in the forms of 'lessons learned' was being sadly anticipated.

\subsubsection{Collaborative approach to funding individual organisations}

Resourcing is a constant issue for many community endeavours. Within Australia, complex systems and organisations are being forced, in the new economic arena, to compete for funding. In the struggle to retain local community services, and thus essential support for people and programs, the most viable approach is to collaborate and generate a collegial approach through engaging in formal partnerships to effect sustainable change. As one community organisation manager explained:

We're going to have to competitively tender for what's historically been our normal block funding, so what that actually means is, who knows whether all of the neighbourhood centres will remain funded, who knows what services will remain funded, because we're all going to have to compete. (HK p. 10)

As a result of this situation a number of neighbourhood centres have joined forces to enter one large funding application as a consortium. This kind of collaboration will hopefully secure the continuation of local community services. All interviewed leaders felt that the structural integrity of the Resilience and Preparedness Working Group would be damaged without representation from emergency services.

\subsubsection{Organisational commitment}

With most of the recovery activities completed or preparing to wind up in 2016, the traditional phases of emergency management came under scrutiny. A new perspective of recovery and preparedness emerged, which envisaged an integrated approach to building resilience in daily life as complementary to building resilience for disaster. In addition, the concept of recovery as an endpoint was challenged. Speaking from their experience of the 2013 fires, participants spoke about recovery as something permanently evolving with the ever-changing shape and nature of the community. There was, therefore, a recognition that although the actual activities of the Resilience and Preparedness Working Group may continue and membership may become tenuous due to less funding and organisational commitment of time and resources, it would nevertheless continue to meet and plan collaborative programmes and strategise for the future stability of the community in the face of potential disaster. All participant leaders agreed that not only does the Resilience and Preparedness Working Group need to develop collaborative approaches to funding, time and planned activities, but also that individual organisations need to commit funding, time and resources to support their representatives to attend. All leaders interviewed said that the unique partnership between emergency services, community services and other organisations formed to deliver preparedness programmes in the community, should continue to be developed and supported by local council, participating organisations and other relevant agencies in the future. 


\section{CONCLUSION AND RECOMMENDATIONS}

Since the 2013 Blue Mountains fires there is a growing appreciation of the connection between emergency and community services. The value of this connection as a resilience-builder in daily living needs to be recognised, as the current climate of rather short contracts and funding limited to recovery processes with an 'end date' fails to recognise the integrated nature of such connections in building resilience during daily living and the flow-on effect into disaster resilience.

The research made a number of recommendations (Redshaw et al., 2015) that have been generalised here for wider application.

Recommendation 1: Maintain key connections

Council, emergency services, and local community services, continue to network and partner in ways that recognise and utilise the capability of each organisation within the community, through adopting strategies that promote a paradigm shift from a top-down approach to emergency planning, response and recovery to being inclusive of the community at every level. This would be evidenced through a re-visioning of the community as active agents in the emergency management process through:

- A genuine integration of local community service providers into all levels of disaster management processes

- Initiating new partnerships, such as local community services' representation on the Local Emergency Management Committee and/or similar committees

- Fostering the continuation of existing partnerships forged in disaster and often left unfunded after recovery

- Implementation of inclusive language, such as the use of full titles rather than acronyms, in all multiagency communications

- Explanation of policies and procedures previously understood as a known within a particular service

- Inclusion of as many as practicable service providers in multiagency emergency management training and preparedness activities, such as table top and scenario-based training

- Resourcing of both emergency and community services to undertake a combined and united approach to community engagement and education around readiness and preparedness in high fire season, when the messages most resonate with the community.

Recommendation 2: Shared responsibility

To promote a shared understanding of the responsibility we each have towards ourselves, our neighbours and our community we need to:

- Clarify roles and responsibilities of all residents and services during periods of natural disaster and emergency

- Reframe the current thinking around individual responsibility for preparedness and readiness, to ensure that those who are unable to implement plans or engage in such activities are supported by neighbours and, when appropriate, the service system

- Involve community groups and individuals in local risk assessment

- Use various community development strategies to ensure household awareness and generate a sense of shared responsibility within neighbourhoods

- Identify and develop community leaders who can be supported to develop awareness and promote participation by residents 
- Provide information, training and education to community members in local neighbourhoods regarding how to support their vulnerable neighbours

- Address the issue of transport for the more vulnerable and isolated within the community, especially in relation to emergency meetings and evacuations.

Finally, we need to reconceptualise disaster preparedness, response and recovery from something 'done' to the community, to something the community expects to be involved in and be a part of. Disaster is woven into the warp and weft of the community fabric: the scars, the memories, the memorials and the evidence of burned houses, blackened landscapes and empty cleared blocks. Natural disaster is almost inevitable and therefore should not be unexpected. The subtle paradigm shift we are advocating is a shift to an expectation of natural disaster occurring at some time, and for this to be reflected in the ethos of building community resilience and sustainability.

\section{REFERENCES}

[1] Australian Bureau of Statistics, Blue Mountains City, Service Age Groups, 2011, available at http://profile.id.com.au/blue-mountains/service-age-groups (accessed 20 June 2016).

[2] Destination NSW., available at http://www.destinationnsw.com.au/tourism/facts-andfigures/regional-tourism-statistics/blue-mountains (accessed 20 June 2016).

[3] Redshaw, S., Ingham, V., Hardgrove, P., Quigley, T. \& Harrison, K., Community Connections: Vulnerability and Resilience in the Blue Mountains, Charles Sturt University: Bathurst, 2015.

[4] Council of Australian Governments. National Strategy for Disaster Resilience Commonwealth Attorney-General's Department. Canberra, 2011.

[5] Bush Fire Bulletin, 36, 2014, available at http://www.rfs.nsw.gov.au/_data/assets/pdf_ file/0020/25922/Bush-Fire-Bulletin-2014-Vol-36-No-2.pdf (accessed 1 June 2016).

[6] Hall, L., Blue Mountains bushfire caused by rotting tree falling on power lines, court hears. Sydney Morning Herald, 2016, available at http://www.smh.com.au/ nsw/blue-mountains-bushfire-caused-by-rotting-tree-falling-on-power-lines-courthears-20160216 gmw177.html\#ixzz4D1zsEYf7 (accessed 20 June 2016).

[7] Murphy, D., Lucky Country. Sydney Morning Herald, 2013, available at http://www.smh. com.au/environment/weather/lucky-country-20131025-2w761.html\#ixzz2ini06N8T (accessed 20 June 2016).

[8] Feneley, R. \& Whelan, J., State of emergency declared as bushfire conditions worsen. Sydney Morning Herald, 2013, available at http://www.smh.com.au/environment/weather/ state-of-emergency-declared-as-bushfire-conditions-worsen-20131020-2vuqu. html\#ixzz4D22sMwAx (accessed 20 June 2016).

[9] Levy, M., NSW bushfires: minister urges residents to leave Blue Mountains. Sydney Morning Herald, 2013, available at http://www.smh.com.au/environment/weather/nswbushfires-minister-urges-residents-to-leave-blue-mountains-20131022-2vzz3.html (accessed 20 June 2016).

[10] Curran, B., After the fires, available at http://www.bluemts.com.au/info/about/after-thefires/ (accessed 20 June 2016).

[11] Deloitte Access Economics Pty Ltd., Scoping Study on a Cost Benefit Analysis of Bushfire Mitigation, 2014, available at http://ausfpa.com.au/wp-content/uploads/2015/11/ AFPA-DAE-report-Amended-Final-2014-05-27.pdf (accessed 20 June 2016).

[12] Legal Aid NSW, available at http://www.legalaid.nsw.gov.au (accessed 20 June 2016). 
[13] Blue Mountains Economic Enterprise., Economic impact report on Blue Mountains Bushfire Emergency October 2013 (Report 3), 2013, available at http://bmee.org.au/ wordpress/wp-content/uploads/2014/09/BMEE-Bushfire-Econ-Impact-Report-3.pdf (accessed 20 June 2016).

[14] Lyons, M., Third Sector: The Contribution of Nonprofit and Cooperative Enterprises in Australia, Sydney: Allen and Unwin, 2001.

[15] Rooney, D., Centres 'Down Under': mapping Australia's neighbourhood Centres and learning. Australian Journal of Adult Learning, 51(2), pp. 203-255, 2011.

[16] Australian Neighbourhood Houses and Centres Association., Response to Scoping Study for a national not-for-profit regulator, 2011, available at http://archive.treasury. gov.au/documents/1983/PDF/Australian_Neighbourhood_Houses_\&_Centres_Association.pdf (accessed 8 June 2016).

[17] West End Community House., Strengthening people and places: the role and value of community and neighbourhood centres, 2011, available at http://www.communityindicatorsqld.org.au/sites/default/files/Role\%20of\%20community\%20centres.pdf (accessed 7 June 2016).

[18] Local Community Services Association., The Contribution of the Not For Profit Sector: Submission to the Productivity Commission Study, 2009, available at http://www. pc.gov.au/inquiries/completed/not-for-profit/submissions/sub144.pdf (accessed 8 June 2016).

[19] Izmir, G., Katz, I., \& Bruce, J., Neighbourhood and Community Centres: results for children, families and communities, 2009. Social Policy Research Centre, Sydney, available at http://www.unsworks.unsw.edu.au/primo_library/libweb/action/dlDisplay.do?vid=UNSWORKS\&docId=unsworks_8463\&fromSitemap=1\&afterPDS=true (accessed 8 June 2016).

[20] Australian Bureau of Statistics., Australian National Accounts: Non-Profit Institutions Satellite Account, 2012-13, 2015, available at http://www.abs.gov.au/ausstats/abs@. $\mathrm{nsf} / \mathrm{mf} / 5256.0$ (accessed 8 June 2016).

[21] Commonwealth of Australia., Impact on service quality, efficiency and sustainability of recent Commonwealth community service tendering processes by the Department of Social Services, 2015. ISBN 978-1-76010-267-8.

[22] Australian Council of Social Services., Submission to Australian Senate Community Affairs Committee Inquiry, 2015, available at http://acoss.wpengine.com/wp-content/ uploads/2015/06/DSS_Senate_Inquiry_ACOSS_submission_2015.pdf (accessed 8 June 2016).

[23] Manock, I., Tertiary emergency management education in Australia. Australian Journal of Emergency Management, 16(2), pp. 4-6, 2001.

[24] Eyre, A., Psychosocial aspects of recovery: practical implications for 23 disaster managers. Australian Journal of Emergency Management, 19(4), pp. 23-27, 2004.

[25] Gordon, R., The social system as site of disaster impact and resource for recovery. Australian Journal of Emergency Management, 19(4), pp. 16-22, 2004.

[26] 2009 Victorian Bushfires Royal Commission, Parliament of Victoria, 2010.

[27] 2012 Queensland Floods Commission of Inquiry, available at http://www.floodcommission.qld.gov.au/publications/final-report (accessed 7 June 2016).

[28] Keelty, M., A Shared Responsibility - The Report of the Perth Hills Bushfire February 2011 Review. Government of Western Australia, available at https://publicsector. 
wa.gov.au/document/inquiry-perth-hills-bushfire-2011-shared-responsibility-report (accessed 6 June 2016).

[29] Childs, M., Morris, M., \& Ingham, V., The rise and rise of clean, white-collar (firefighting) work. Disaster Prevention and Management: An International Journal, 13(5), pp. 409-414, 2004.

https://doi.org/10.1108/09653560410568534

[30] Paton, D., \& Johnston, D., Disaster Resilience: An Integrated Approach, Charles C Thomas Pub Ltd, 2006.

[31] Sewell, F., Reflections on community response to bushfires, response article in NCQ 5(4) pp. 11-25 of Goodman, Healey and Boulet. New Comm Quarterly, 5, pp. 16-20, 2007.

[32] Schraagen, J.M. \& van den Ven, J., Human factors aspects of ICT for crisis management. Cognition, Technology and Work, 13(3), pp. 175-187, 2011.

https://doi.org/10.1007/s10111-011-0175-6

[33] Kapucu, N. \& Garayev, V., Collaborative decision-making in emergency and disaster management. International Journal of Public Administration, 34(6), pp. 366-375, 2011. https://doi.org/10.1080/01900692.2011.561477

[34] Owen, C., The changing nature of emergency services multi-agency coordination. Presented at the Bushfire CRC \& AFAC, Sydney, Australia, 2011.

[35] Ross, H. \& Berkes, F., Research approaches for understanding, enhancing, and monitoring community resilience. Society \& Natural Resources: An International Journal, 27(8), pp. 787-804, 2014. https://doi.org/10.1080/08941920.2014.905668

[36] Ingham, V., Multimodal research applied to decision making by incident controllers on the fireground. Material Inventions: Applying Creative Research, eds E. Barrett \& B. Bolt, London and New York: I.B. Tauris Co \& Ltd. Hardback, chap 4, 2014. 